\title{
Evaluation of Nutritional Status in Relation to the Cognitive Performance of Medical Students at Oman Medical College
}

\author{
Firdous Jahan, P.J.Joseph Francis, Rizwan Qasim, Zaid Mukhlif, Zoya Shaikh ${ }^{*}$ \\ Family Medicine Department, Oman Medical College, Sultanate of Oman
}

Copyright@2018 by authors, all rights reserved. Authors agree that this article remains permanently open access under the terms of the Creative Commons Attribution License 4.0 International License

\begin{abstract}
Objective: Dietary assessment to describe eating practices and asses the nutritional status of students in relation to the cognitive performance of students by Mini-Mental State Examination. Methods: A cross-sectional study was conducted using a food frequency questionnaire, Mini mental state examination, anthropometric measurements, and blood analysis for measuring hemoglobin $(\mathrm{Hb})$ and glucose levels. Third year medical students of Oman medical college Sohar campus (Sample size, $\mathrm{N}=80$ ) were involved in this study. Statistical Analysis was done using the food frequency, MMSE and blood analysis data to study the dietary patterns, nutrition status and cognitive performance of the students. Results: The data revealed low intake of legumes, eggs and red meat (mutton/beef), hence low protein intake by majority of students. $47.5 \%$ of the students consumed only two meals in a day. $20.9 \%$ of the students were underweight, $13.4 \%$ were overweight and 9\% were obese. Physical inactivity was present in $51.2 \%$ of the students. Low hemoglobin $(\mathrm{Hb}<12 \mathrm{mg} / \mathrm{dl})$ and low glucose level $(<3.9 \mathrm{mmol} / \mathrm{L})$ was observed in $32 \%$ and $28.7 \%$ of study sample respectively. Low MMSE score among $11.6 \%$ subjects indicated mild cognitive impairment. A significant correlation existed between MMSE and glucose level $(\mathrm{p}<0.05)$. Conclusion: A strategy is required to monitor the nutrition of young Omani adults in order to improve health status and prevent deficiency diseases. There is an urgent requirement to promote healthy food choices and lifestyle among medical students.
\end{abstract}

Keywords Nutrition, Cognitive Performance, Medical Students, Public Health, Anemia

\section{Introduction}

Adequate nutrition plays a vital role in human physical and mental development. Appropriate diet and lifestyle has a positive influence on the cognitive development and academic performance of students [1-3]. Nutrition also affects cognitive functioning. Insufficient nutrition could lead to impaired cognitive development [4] and academic performance [5, 6]. Unhealthy diet and eating habits among young adults is a major topic of concern at present [7]. Young adults are more vulnerable to poor eating habits due to rapid changes in physical growth and psychosocial development; hence, their dietary requirements are not fulfilled [8-10]. Meal skipping, eating away from home, snacking and fast food consumption are some of the unhealthy food habits among young adults $[9,10]$. University students in particular, adopt poor eating habits due to stress and lack of time [11, 12], which can pose a negative impact in the later adulthood [13]. Moreover, research has shown low intake of fruits and vegetables by university students $[14,15]$. Furthermore, the choices of food made by young adults, especially university students are based on cost of food [16].

Lack of knowledge about healthy food choices can negatively affect the nutritional status [16]. Prevalence of anaemia, skipping breakfast, inappropriate anthropometric measurements have been associated with poor academic performances among students [1]. Moreover, a number of medical conditions may arise due to eating disorders [17]. Abnormally low level of glucose in blood stream, known as hypoglycaemia, can be triggered due to malnutrition[18]. Blood glucose levels are known to affect cognitive performance. In fact, hypoglycaemia can cause disruption of cognitive functioning [19]. Iron deficiency anaemia and cognitive dysfunction are linked [20,21]. Iron deficiency is the most common cause of anemia worldwide. Impaired physical and cognitive developments are some of the serious health consequences of anaemia. Iron deficiency anemia significantly affects cognitive performance among adults [22]. 
In the eastern Mediterranean region, Iron deficiency anaemia is an important public health concern[23]. In central and western Europe, unhealthy food habits and inappropriate weight was observed among medical students [24, 25]. In Egypt, a cross sectional study found majority of students were overweight and obese due to improper food habits and low physical activity [26]. The assessment of nutrition and health status, nutrients intake, and physical activity among Saudi medical students revealed the deficiencies of essential nutrients and the prevalence of obesity [27]. According to the global nutrition report by World Health Organization (WHO), anaemia in women of reproductive age, and adult overweight and obesity overlap in Oman. The prevalence rate of anaemia in women of reproductive age is $35.1 \%$ and adult over weight and obesity prevalence is $67.4 \%$ in Oman [28].

Only a few studies have been conducted in the Middle East regions to evaluate the existence of malnutrition among different age groups. Only little information is available regarding nutrition of Omani females of reproductive age. In Oman, unhealthy eating habits among adolescents, similar to those practiced in the west have been observed which may lead to diet-related chronic diseases [29]. Although, studies based on the nutritional status of young adults, especially university students are still nascent. The progress of a nation is dependent on the young population which includes medical students as the future doctors. Evaluation of nutritional status and lifestyle of medical students is required in order to maintain a healthy mind and body [1, 30].

The aim of our study was to evaluate the nutritional status in relation to the cognitive performance of medical students at Oman Medical College, which is situated in Sohar, the main city of Al Batinah North Governorate in Oman. Sohar is also known as the port city on the northern coast (Al Batinah coast) of Oman. This industrial hub is Oman's fifth most populated city. The origin of Omani population is predominantly Arab, Baluchi and African. They belong to the middle income group and the sources of income mostly include oil export, industry, agriculture, tourism and trade.

Oman Medical College (OMC) is a private co-educational college. Its curriculum and school leadership are provided by West Virginia University, U.S.A., the academic partner. The Doctor of Medicine (MD) Program of Oman Medical College consists of six years of coursework. It comprises of two years of premedical studies, two years of basic biomedical science, and two years of clinical training. A complete one-year clinical internship in a recognized teaching hospital prior to medical licensure is compulsory for the medical graduates. Although, the students are taught about various health topics and diseases like diabetes, anemia, obesity and other deficiency diseases, there is no formal curriculum or course work for the awareness of healthy eating habits and nutrition.

\section{Materials \& Methods}

\subsection{Study Participants and Study Setting}

The study design and methods were carried out from May 2017 until July 2017. A cross-sectional study approach, based on previously validated questionnaire was adopted in this study. Third year medical students of Oman Medical College (Sohar Campus) participated with consent. A self-administered questionnaire on eating habits was used, adopted from previous published studies [31, 32]. The questionnaire consisted of three parts. The first part included questions concerning demographic data; such as age, gender, education level, marital status, ethnicity and living circumstances, and lifestyle; such as smoking, alcohol intake and physical activity. The second part of the questionnaire consisted of questions on eating habits, food frequency and type of meals consumed (10 items), such as frequency of meals, type of meal, frequency of vegetables and fruits consumption, daily water intake, consumption of fast food, etc. In the third part, questions on psychological factors that influenced dietary habits of respondents were included.

\subsection{Anthropometric Measurements}

The body mass index (BMI) of the selected group of students was determined using the basic anthropometric parameters (body height and weight). The body height and weight was measured on a certified medical scale with a height meter and the waist circumference measured with a tailor's measuring tape. The anthropometric measurements were conducted in accordance with the rules adopted in anthropometry [33]. The BMI was interpreted according to the WHO guidelines [34].

\subsection{Mini-Mental State Examination Questionnaire}

The Mini-Mental State Examination (MMSE) was used to assess global cognitive function. It was introduced by Folstein et al in 1975 [35]. The MMSE includes cognitive domains such as orientation for time and place, language and visuospatial skills, comprehension, immediate recall of three words and basic motor skills [35]. The maximum test sum-score is 30 points (theoretical range). A score above 27 points is considered to be within the normal range. A score below 24 points often corresponds to cognitive impairment. The MMSE takes only 5-10 minutes to administer and is therefore practical to use repeatedly and routinely. Thus, MMSE questionnaire was used in this study for the evaluation of cognitive performance of the study sample. 


\subsection{Blood Test Analysis}

Blood samples were collected by using aseptic technique uniformly from all the subjects at same time. Haemoglobin $(\mathrm{Hb})$ and blood glucose levels were estimated through laboratory test. The blood sample collection, testing and analysis were conducted by a standard clinical laboratory.

\subsection{Statistical Analysis}

The data obtained from the questionnaires and blood test was analysed using the Statistical Package for the Social Sciences (SPSS) Program for windows. This involved descriptive statistics and correlational analysis among various study parameters.

\section{Results}

This study involved third year medical students of Oman medical college, Sohar. The initial sample size was 88 (83 females and 5 males). Since the number of male students were very low (5.7\%), the analysis was carried out for female students only. However, three female subjects could not provide the complete information needed for this study. Thus, the actual sample size was 80. Interestingly, $75 \%$ of the students were below 20 years of age. $25.8 \%$ belonged to the age group of $20-25$ years and $1.3 \%$ of students were of age 25-30 years. The Omani nationals made up $78.8 \%$ of the study sample, the rest $21.3 \%$ were Non-Omani students, belonging to the Middle Eastern and Asian countries. Majority of student's lived in the hostel (87.5\%). (Table 1)

Table 1. Demographic, health and dietary characteristics of students (female) based on Questionnaire

\begin{tabular}{|c|c|}
\hline Characteristic & Percentage of students(\%); $(\mathrm{N}=\mathbf{8 0})$ \\
\hline $\begin{array}{c}\text { Age (years): } \\
<20 \\
20-25 \\
25-30\end{array}$ & $\begin{array}{l}75 \\
24 \\
1.0\end{array}$ \\
\hline $\begin{array}{c}\text { Nationality: } \\
\text { Omani } \\
\text { Non-Omani }\end{array}$ & $\begin{array}{l}78.8 \\
21.2 \\
\end{array}$ \\
\hline $\begin{array}{c}\text { Health Problem: } \\
\text { none } \\
\text { Thalassemia } \\
\text { Stress/anxiety } \\
\text { Iron Deficiency Anemia } \\
\text { Other }\end{array}$ & $\begin{array}{c}88.8 \\
3.8 \\
2.5 \\
1.3 \\
3.6\end{array}$ \\
\hline $\begin{array}{c}\text { Living in : } \\
\text { Hostel } \\
\text { Home } \\
\end{array}$ & $\begin{array}{l}87.5 \\
12.5 \\
\end{array}$ \\
\hline $\begin{array}{c}\text { Abnormal Symptoms: } \\
\text { Bleeding Gums } \\
\text { Constipation } \\
\text { Dizziness } \\
\text { Diarrhea } \\
\text { Dyspnea } \\
\text { Headache } \\
\text { Fatigue } \\
\text { Loss of Appetite } \\
\text { Paresthesia } \\
\text { Weight loss } \\
\text { Menorrhagia } \\
\text { Palpitation } \\
\text { Weakness }\end{array}$ & $\begin{array}{c}8.8 \\
8.8 \\
18.8 \\
5 \\
6.3 \\
31.3 \\
23.8 \\
16.3 \\
7.5 \\
11.3 \\
5 \\
6.3 \\
15 \\
\end{array}$ \\
\hline $\begin{array}{c}\text { Physical Activity : } \\
\text { No } \\
\text { Yes(<3 days a week) } \\
\text { Yes(>3days a week) }\end{array}$ & $\begin{array}{l}51.2 \\
32.5 \\
16.3\end{array}$ \\
\hline $\begin{array}{c}\text { Family History : } \\
\text { None } \\
\text { Diabetes } \\
\text { G6PD anemia } \\
\text { Iron deficiency anemia } \\
\text { Sickle cell anemia } \\
\text { Thalassemia } \\
\text { Other }\end{array}$ & $\begin{array}{c}62.4 \\
2.3 \\
5.7 \\
6.8 \\
8.0 \\
3.4 \\
11.4\end{array}$ \\
\hline
\end{tabular}




\begin{tabular}{|c|c|}
\hline $\begin{array}{c}\text { Type of Food : } \\
\text { Homemade } \\
\text { Cafeteria }\end{array}$ & 26.3 \\
\hline No. of Meals : & 73.7 \\
$\mathbf{1}$ & 2.5 \\
$\mathbf{2}$ & 47.5 \\
$\mathbf{4}$ & 43.8 \\
\hline BMI: & 6.3 \\
\hline underweight & 20.9 \\
Normal & 56.7 \\
overweight & 13.4 \\
Obese & 9.0 \\
\hline Cognitive Performance : & 11.6 \\
Mild Cognitive impairment & 88.4 \\
No Cognitive impairment & 32 \\
\hline Low Hemoglobin & 28.7 \\
\hline Female (<12mg/dl) & 7.5 \\
\hline Low Glucose (<3.9mmol/L, hypoglycemia) & 7.9 \\
\hline High Blood Pressure & \\
\hline
\end{tabular}

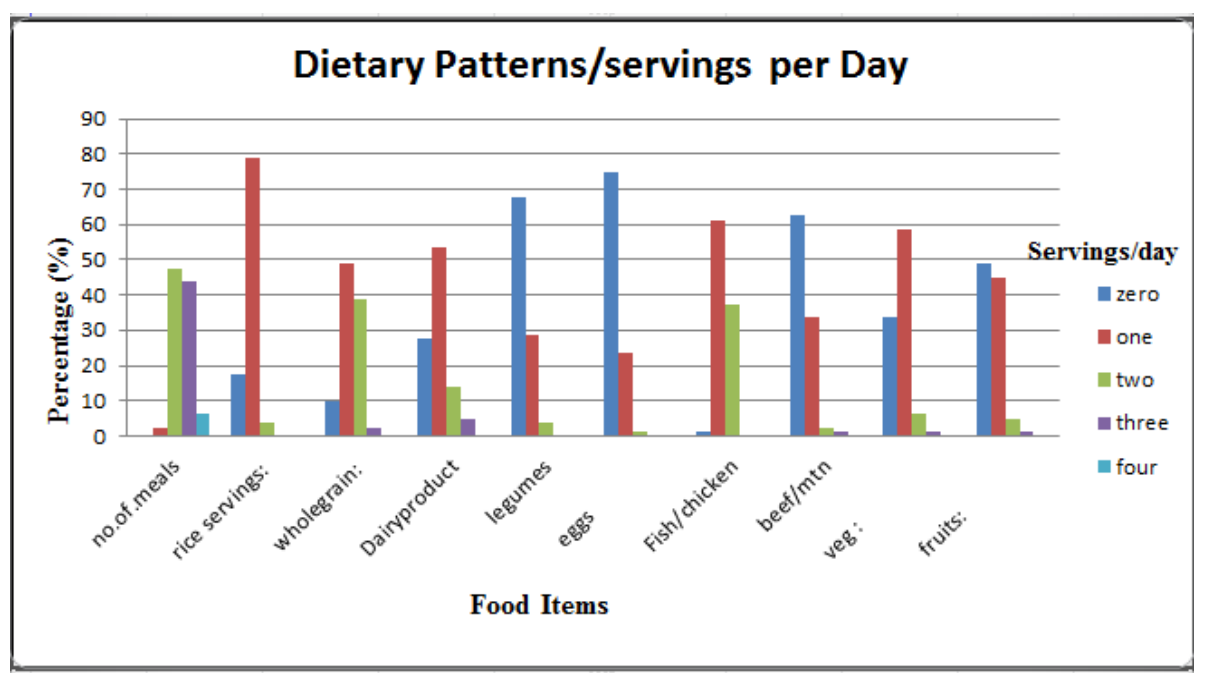

Figure 1. Dietary pattern of students based on servings of different food items per day

The data from the questionnaire filled by the students revealed that $3.8 \%, 2.5 \%$, and $1.3 \%$ of the students suffered from Thalassemia, stress/anxiety and Iron deficiency anemia respectively. Also, the prevalence of abnormal symptoms like Bleeding gums (8.8\%) constipation (8.8\%) dizziness (18.8\%), diarrhea (5\%), Dyspnea (6.3\%), Headache (31.3\%), Fatigue (23.8\%), Loss of appetite (16.3\%), paresthesia (7.5\%). Weightless (11.3\%), Menorrhagia (5\%), palpitation (6.3\%) and weakness (15\%) was reported. Family history of Diabetes, G6PD Anemia, Iron deficiency Anemia, Sickle cell anemia and Thalassemia was present in 2.3\%, 5.7\%, 6.8\% 8\% and $3.4 \%$ of the study sample (Table 1 ).

Surprisingly, $51.2 \%$ of the students did not involve in any kind of physical activity, while $32.5 \%$ and $16.3 \%$ of the students were physically active for $(<3$ days a week) and ( $>3$ days a week) respectively. While $20.9 \%$ were underweight, $9 \%$ and $13.4 \%$ of the students were found to be obese and overweight respectively. In addition, $7.9 \%$ of the female students had increased waist circumference ( $>88 \mathrm{~cm}$ female). High blood pressure was observed among $7.5 \%$ of the students (Table 1).Cafeteria food was consumed by $73.7 \%$ of the students and $47.5 \%$ of the students consumed only 2 meals a day (Figure: 1 ).

There was a very low consumption of legumes, eggs and red meat (mutton/beef), hence low protein intake by majority of students (Figure 1). The blood test results indicated Low hemoglobin $(\mathrm{Hb})$ in $32 \%$ of female students $(<12 \mathrm{mg} / \mathrm{dl})$. Low glucose levels $(<3.9 \mathrm{mmol} / \mathrm{L})$ (hypoglycemia) was observed among $28.7 \%$ of subjects. The MMSE questionnaire evaluation indicated mild Cognitive impairment among $11.6 \%$ of the students (Table 1).

Upon statistical analysis, a significant correlation was observed between MMSE and glucose levels $(p<=0.05$ ). Hence, hypoglycemia may attribute towards the mild cognitive impairment. Students living in the hostel are prone to skipping breakfast and consuming cafeteria food 
which is unhealthy. As discussed above, iron deficiency anemia also affects cognitive functioning [21]. Interestingly, a positive trend towards correlation was found between the type of food students consumed (cafeteria or homemade) and glucose levels $(p=0.053)$. Physical activity and BMI were also found to be significantly correlated $(\mathrm{p}<=0.05)$.

\section{Discussion}

Our study revealed some of the poor eating practices that exist among students of Oman medical college, such as low intake of protein rich food (legumes, eggs, and beef/meat), consuming only 2 meals in a day and eating food from the cafeteria. This observation is in agreement to the finding of a recent study which evaluated the food consumption patterns of undergraduate students of Sultan Qaboos University, where the intake of eggs and legumes (per day) among the students was found to be low $(<15 \%)$ [36]. Also, a Malaysian study reported that majority of females did not consume the recommended nutrient intake (RNI) for proteins [37]. Physical inactivity was displayed by the majority of students in our study (51.2\%). This is parallel to the study conducted in Saudi Arabia where $64.4 \%$ of the students were physically inactive [27]. Previous studies have also indicated lack of physical activities among majority of young Omani adults [38, 39].

Surprisingly, the underweight (20.9\%) students were higher than the obese (9\%) and overweight (13.4\%) in our study sample. This is in accordance to the previous studies held in Malaysia, Pakistan and Oman. The Malaysian study involving university students reported that the proportion of underweight students was higher than the obese and overweight students [40]. Similar finding was reported by a study conducted in Pakistan, suggesting that being underweight could be an upcoming matter of concern among medical students [41]. Furthermore, a recent study held at the Sharqiya University of Oman reported that 29\% of the female students were underweight, while $27 \%$ were overweight and only $6 \%$ were obese [42].

Blood analysis of medical students in our study revealed that a significant number of students had low hemoglobin (32\%) and low glucose levels (28.7\%). Supportively, previous studies suggest that anemia is currently prevalent among female university students. In United Arab Emirates (UAE), $26.6 \%$ of the female students of University of Sharjah were anemic $(\mathrm{Hb}<12 \mathrm{~g} / \mathrm{dl})[43]$. In Saudi Arabia, a study revealed that $21.6 \%$ of adult females were found to be anemic[44].In Bangladesh, a cross sectional study was reported that $55.3 \%$ of the university students were anemic[45]. However, in Oman, the latest update on the prevalence of Iron Deficiency Anemia was reported in 2005, by the ministry of health, Oman. Accordingly, 38.8\% of the Omani women of reproductive age were anemic [46].
The low blood sugar found among $28.7 \%$ of the subjects may be attributed to unhealthy eating practices among the students. Since majority of students (47.5\%) consume only 2 meals in a day, the habit of skipping breakfast may have a negative impact on the blood sugar and metabolism [47]. In our study sample, low MMSE score among $11.6 \%$ subjects indicated mild cognitive impairment. Also, significant correlation existed between MMSE and glucose level $(p<0.05)$. It is known that the human brain requires continuous supply of glucose for its proper functioning [48]. Data from the previous studies indicate that low blood glucose levels can lead to impaired cognition [49]. Thus, skipping breakfast may cause the glucose levels to drop which can eventually affect the cognitive performance of students [50]. This may explain the correlation between MMSE and glucose levels ( $p<=0.05$ ) in our study.

\section{Conclusions}

This study unveiled the unhealthy dietary patterns among the medical students. Low protein intake and condition of hypoglycemia may increase the severity of metabolic disorder among the population .As future doctors, medical students need to be aware about the healthy food choices. An elaborate study is required to investigate the incidence of Iron deficiency anemia among young Omani adults, especially women. A strategy is required to monitor the nutrition of young Omani adults in order to improve the health status and prevent deficiency diseases. Several studies across the countries reveal the prevalence of inappropriate nutrition among young adults, due to inadequate food intake and poor dietary habits. In Oman nutritional disorders like anaemia, hypoglycaemia and obesity are prevalent among young adult population. However, there is absence of detailed information on nutritional status, universities and colleges can initiate such study and to establish the preventive intervention programs. Such strategies can especially benefit medical colleges in order to train them as future health personnel.

\section{Acknowledgements}

We would like to thank the management team of Oman medical college for allowing us to conduct this study.

\section{REFERENCES}

[1] Ghosh, S. and H. Saha, The role of adequate nutrition on academic performance of college students in North Tripura. International Journal of Health Sciences and Research, 2013. 3(8): p. 56-63.

[2] Sigman, M., et al., Cognitive abilities of Kenyan children in relation to nutrition, family characteristics, and education. 
Child development, 1989: p. 1463-1474.

[3] Lisa, M., The correlation between eating breakfast and school performance. Am. J. Clin Nutr, 1998. 65: p. 7795-9845.

[4] Johnston, F.E., et al., Interaction of nutritional and socioeconomic status as determinants of cognitive development in disadvantaged urban Guatemalan children. American Journal of Physical Anthropology, 1987. 73(4): p. 501-506.

[5] Taras, H., Nutrition and student performance at school. Journal of school health, 2005. 75(6): p. 199-213.

[6] Ahmed, A.F. and R.R.A. El-Ghany, Nutritional Status Assessment of boarding Students At Hadhramout University (YEMEN).

[7] Nelson, M.C., et al., Emerging adulthood and college-aged youth: An overlooked age for weight-related behavior change. Obes, 2008. 16.

[8] Chin, Y.S. and N.M. Mohd, Eating behaviors among female adolescents in Kuantan District, Pahang, Malaysia. Pak J Nutr, 2009. 8.

[9] Savige, G.S., et al., Food intake patterns among Australian adolescents. Asia Pac J Clin Nutr, 2007. 16.

[10] Shi, Z., et al., Socio-demographic differences in food habits patterns of school children and adolescents in and preferences of school adolescents in Jiangsu Province, China. Eur J Clin Nutr, 2005. 59.

[11] Rubina, A., et al., Knowledge and practice of healthy lifestyle and dietary habits in medical and non-medical students of Karachi, Pakistan. J Pak Med Assoc, 2009. 59.

[12] Webb, E., et al., An update on British medical students' lifestyles. Med Educ, 1998. 32.

[13] Silliman, K., K. Rodas-Fortier, and M. Neyman, A survey of dietary and exercise habits and perceived barriers to following a healthy lifestyle in a college population. Californian J Health Promot, 2004. 2.

[14] Moy, F.M., et al., Breakfast skipping and its associated factors among undergraduates in a public university in Kuala Lumpur. Mal J Nutr, 2009. 15.

[15] Huang, T.T.K., et al., Assessing overweight, obesity, diet and physical activity in college students. J Am Coll Health, 2003. 52.

[16] Gan, W.Y., et al., Differences in eating behaviours, dietary intake and body weight status between male and female Malaysian university students. Mal J Nutr, 2011. 17.

[17] Grace, T.W., Health problems of college students. 1997.

[18] National Health Services, N. Hypoglycemia. 2015; Available from:

http://www.nhs.uk/Conditions/Hypoglycaemia/Pages/Introd uction.aspx

[19] Feldman, J. and I. Barshi, The effects of blood glucose levels on cognitive performance: A review of the literature. 2007.

[20] Saratha, A., et al., Prevalence of anaemia among young adult female students in a medical teaching institution in Pondicherry. Indian journal of maternal and child health,
2010. 12(4): p. 1-8.

[21] Ukkirapandian, K., et al., A clinical study on effects of iron deficiency anaemia on cognitive function among undergraduate paramedical students. International Journal of Medical Science and Public Health, 2014. 3(8): p. 948-950.

[22] Khedr, E., et al., Iron states and cognitive abilities in young adults: neuropsychological and neurophysiological assessment. European Archives of Psychiatry and Clinical Neuroscience, 2008. 258(8): p. 489-496.

[23] World Health Organisation, W. Anaemia. 2011; Available from: http://www.who.int/topics/anaemia/en/

[24] Kolarzyk, E., et al., Nutritional status and food choices among first year medical students. Open Medicine, 2012. 7(3): p. 396-408.

[25] Bede, F.W.-A.K., Eating practices and nutritional status of second year medical students in three state universities. 2014.

[26] Bakr, E., N. Ismail, and H. Mahaba, Impact of life style on the nutritional status of medical students at Ain Shams University. The Journal of the Egyptian Public Health Association, 2001. 77(1-2): p. 29-49.

[27] Allam, A.R., et al., Nutritional and health status of medical students at a university in Northwestern Saudi Arabia. Saudi medical journal, 2012. 33(12): p. 1296-1303.

[28] Haddad, L., Global Nutrition Report 2016: FROM PROMISE TO IMPACT: ENDING MALNUTRITION BY 20302016.

[29] Musaiger, A.O., Nutritional status and dietary habits of adolescent girls in Oman. Ecology of food and nutrition, 1994. 31(3-4): p. 227-237.

[30] Ivanovic, D. and M. Marambio, Nutrition and education. I. Educational achievement and anthropometric parameters of Chilean elementary and high school graduates. Nutrition reports international (USA), 1989.

[31] Yahia, N., et al., Eating habits and obesity among Lebanese university students. Nutrition journal, 2008. 7(1): p. 1.

[32] Alizadeh, M. and K. Ghabili, Health related lifestyle among the Iranian medical students. Res Biol Sci, 2008. 3(1): p. 4-9.

[33] Drozdowski, Z., Anthropometry in physical education. AWF, Poznań, 1998.

[34] Organization, W.H., Obesity: preventing and managing the global epidemic. 2000: World Health Organization.

[35] Folstein, M.F., S.E. Folstein, and P.R. McHugh, "Mini-mental state": a practical method for grading the cognitive state of patients for the clinician. Journal of psychiatric research, 1975. 12(3): p. 189-198.

[36] Shahana, S.S.I.N.K. and B.E.P.V. Singh, Food Consumption Patterns of Male and Female University Students in Oman. 2016.

[37] WY, G. and H. AS, Differences in eating behaviours, dietary intake and body weight status between male and female Malaysian University students. Malaysian Journal of 
Nutrition, 2011. 17(2).

[38] Mabry, R., et al., Descriptive epidemiology of physical activity among Omani adults: the Oman World Health Survey, 2008. Eastern Mediterranean Health Journal, 2016. 22(2): p. 103.

[39] Al-Habsi, A. and H. Kilani, Lifestyles of adult Omani women: cross-sectional study on physical activity and sedentary behaviour. Sultan Qaboos University Medical Journal, 2015. 15(2): p. e257.

[40] Alam, P., Nutritional status and eating practices among university students in selected universities in Selangor, Malaysia. Asian Journal of Clinical Nutrition, 2012. 4(3): p. 77-87.

[41] Afzal, M., F. Rizvi, and A.M. Rajput, Categories of Overweight and Underweight Students According to Body Mass Index in a Private Medical College. Journal of Islamabad Medical \& Dental College (JIMDC), 2015. 4(1): p. 27-30.

[42] Labban, L., “The Prevalence of Overweight and Obesity Among A'Sharqiyah University Students in Sultanate of Oman: A Randomized Study”. EC Nutrition, 2015. 3.1: p. 521-527.

[43] Sultan, A.H., Anemia among female college students attending the University of Sharjah, UAE: prevalence and classification. J Egypt Public Health Assoc, 2007. 82(3-4): p. 261-71.
[44] Al-Assaf, A.H., Anemia and iron intake of adult Saudis in Riyadh City-Saudi Arabia. Pakistan Journal of Nutrition, 2007. 6(4): p. 355-358.

[45] Shill, K.B., et al., Prevalence of iron-deficiency anaemia among university students in Noakhali region, Bangladesh. Journal of Health, Population and Nutrition, 2014. 32(1): p. 103.

[46] Petry, N., et al., The proportion of anemia associated with iron deficiency in low, medium, and high human development index countries: A systematic analysis of national surveys. Nutrients, 2016. 8(11): p. 693.

[47] Service, N.H. Hypoglycaemia (low blood sugar) - Causes 2015 [cited 2016 12-6]; Available from: http://www.nhs.uk/Conditions/Hypoglycaemia/Pages/Cause s.aspx.

[48] Howarth, C., P. Gleeson, and D. Attwell, Updated energy budgets for neural computation in the neocortex and cerebellum. Journal of Cerebral Blood Flow \& Metabolism, 2012. 32(7): p. 1222-1232.

[49] Warren, R.E. and B.M. Frier, Hypoglycaemia and cognitive function. Diabetes, Obesity and Metabolism, 2005. 7(5): p. 493-503.

[50] Morris, N. and P. Sarll, Drinking glucose improves listening span in students who miss breakfast. Educational research, 2001. 43(2): p. 201-207. 